\title{
Comparison of quick and slow thaw methods of producing cryoprecipitate antihaemophilic factor from fresh and 24-hour-old blood
}

\author{
A. L. BLOOM, J. C. GIDDINGS, BERYL BEVAN, M. LETTON, AND \\ R. J. DRUMMOND \\ From the Institute of Pathology, the Royal Infirmary, Cardiff, and the Welsh Regional Transfusion Centre, \\ Rhyd-lafar, Cardiff
}

SYNOPSIS Cryoprecipitate antihaemophilic factor concentrate was prepared from fresh and 24-hourold blood by quick and slow thaw methods. Recovery of factor VIII was greater by the slow thaw method and there was less loss into the supernatant plasma. Cryoprecipitate produced from fresh blood contained more factor VIII than that produced from 24 -hour-old blood so that the most potent concentrate was produced from fresh blood by the slow thaw process. An adequate therapeutic preparation was, however, produced by the slow thaw method using 24-hour-old blood and it is suggested that this procedure could be adopted in order to supplement supplies.

Haemophilic blood is deficient in antihaemophilic factor (factor VIII), a deficiency which can be partially corrected by transfusions of fresh frozen plasma or, more effectively, by plasma fractions containing high concentrations of antihaemophilic factor. Until recently the preparation of concentrated antihaemophilic factor from animal or human blood involved large-scale fractionation processes which were beyond the scope of most hospital laboratories and blood transfusion centres. In 1965 Pool and Shannon described a simple cold precipitation method for the production of antihaemophilic factor concentrate which does not require such elaborate equipment. Cryoprecipitate antihaemophilic factor is now an established therapeutic material but its effectiveness and ease of administration have led to a steadily increasing demand. It was therefore considered desirable to examine various techniques for the preparation of cryoprecipitate in order to determine those which are the simplest, most convenient, and yet effective.

The original method of Pool and Shannon (1965) is based upon the fact that when plasma is frozen and allowed to thaw slowly at $+4^{\circ} \mathrm{C}$ the antihaemophilic factor remains as a precipitate which can be separated by centrifugation. Using a closed double plastic bag system the blood is processed under aseptic conditions thus allowing recovery of both the cryoprecipitate and the antihaemophilic Received for publication 12 July 1968. factor-deficient whole blood. Brown, Hardisty, Kosoy, and Bracken (1967) modified this technique. They sacrificed the closed bag system and transferred the plasma into larger bags in order to achieve more rapid freezing. They also accelerated the thawing process by incubating the frozen plasma at +6 to $+8^{\circ} \mathrm{C}$. Using this method they claimed an increased yield of antihaemophilic factor. With both methods antihaemophilic factor was prepared from fresh plasma. There is evidence, however, that although antihaemophilic factor is labile, considerable activity may persist in bank blood which is 24 hours old (Penick and Brinkhous, 1956; Wolf, 1959; Goldstein, Bunker, and McGovern, 1964; Preston, 1967). In certain circumstances it may be more convenient to prepare cryoprecipitate from 24-hour-old blood if it can be shown that a worthwile yield of antihaemophilic factor is achieved.

The object of this paper is to describe the results of a study of the cryoprecipitate antihaemophilic factor prepared by the slow thaw method of Pool and Shannon (1965) and by a modification of the quick thaw method of Brown et al (1967), in each case using fresh blood and blood stored for 24 hours at $+4^{\circ} \mathrm{C}$. The recoveries in vitro and in vivo of factor VIII by each method are compared, and it will be shown that although the slow thaw method using fresh blood produced the most potent concentrate, an active preparation can be prepared from blood which is 24 hours old. 
METHODS

COLLECTION OF BLOOD Blood was collected at routine donor sessions into Fenwal JD-2 double plastic packs. 'Fresh blood' was taken at local donor sessions, immediately cooled, and transported as soon as possible to the transfusion centre. Timing was so arranged that plasma transferred to the satellite pack (see below) was always completely frozen within four hours of blood collection. 'Twenty-four-hour'-old blood was also refrigerated after donation, transported less urgently to the transfusion centre, and stored at $+4^{\circ} \mathrm{C}$. It was processed the day after donation. In each case a small sample of donor blood was taken into the same proportion of identical anticoagulant and stored at $+4^{\circ} \mathrm{C}$ until the cryoprecipitate process was commenced. This sample was centrifuged immediately before the packs were processed, the plasma removed, and placed immediately in store at $-30^{\circ} \mathrm{C}$. At the time of treatment of patients this was assayed as donor plasma, $i e$, frozen fresh plasma or frozen 24-hour-old plasma.

PREPARATION OF CRYOPRECIPITATE The slow thaw method was similar to that described by Pool and Shannon (1965). The blood was centrifuged in a refrigerated centrifuge. The plasma was transferred to the satellite pack and the volume assessed by weight. The plasma pack was frozen in an alcohol-dry ice mixture and together with the attached red-cell pack was placed overnight to thaw in a refrigerator at $+4^{\circ} \mathrm{C}$. The following day the cryoprecipitate was deposited by centrifugation and most of the supernatant plasma returned to the packed red cells. A small sample of supernatant plasma was removed and stored at $-30^{\circ} \mathrm{C}$ for subsequent assay and 5 to $10 \mathrm{ml}$ was left in the satellite pack to dissolve the cryoprecipitate. The two packs were separated and the cryoprecipitate stored at $-30^{\circ} \mathrm{C}$. It was used within two weeks of preparation. The reconstituted antihaemophilicfactor-deficient whole blood was stored for routine use.

The quick thaw method was similar to that described by Brown et al (1967) except that the double packs were retained. The steps were identical to the slow thaw method but the frozen plasma was immediately thawed in a water bath at +6 to $+8^{\circ} \mathrm{C}$. Thawing took only about two hours and when complete the cryoprecipitate was collected as in the slow thaw method.

No special effort was made to increase the yield of factor VIII for the purposes of this investigation other than as described above and the results are representative of those obtained routinely in this centre.

For administration to patients the packs of cryoprecipitate were thawed for a few minutes at $37^{\circ} \mathrm{C}$ and kneaded to dissolve the precipitate. The contents of the requisite number of packs were aspirated into a disposable syringe and the volume contained in each pack was noted. Small samples from each cyroprecipitate pack and from the pooled dose were taken for immediate factor VIII assays. The pooled cryoprecipitate solution was then administered to the patient by intravenous injection. No attempt was made to match ABO groups but, where possible, Rh-positive cryoprecipitate was not administered to $\mathrm{Rh}$-negative recipients.
FACTOR VIII ASSAYS These were performed by the method of Pool and Robinson (1959a) modified and 음 controlled as described by Bloom and Emmanuel (1968). Assays were performed on fresh plasma from patients before and after each dose and on freshly thawed samples of cryoprecipitate, donor plasma, and supernatant plasma. For assay the cryoprecipitate solution was diluted one part in five with plasma from a severely affected haemophiliac except that when high assay figures were recorded a 1 in 10 dilution was prepared.

EXPRESSION OF RESULTS Factor VIII activity is expressed as units, one unit being equivalent to $1 \mathrm{ml}$ of fresh average normal plasma. The activity of the donor plasma, cryoprecipitate, and supernatant was determined from the results of assay of freshly thawed samples and the measured volume. The dose of cyroprecipitate administered to each patient was determined from the sum of the units contained in individual packs and checked by the assay of the pooled dose. Expected levels of factor VIII in patients were determined as described by Biggs and Matthews (1966) except that the plasma volume was determined from the weight and haematocrit of the patients at the time of treatment (Mollison, 1967). The recovery in vivo was determined by expressing the observed rise of factor VIII as a percentage of the expected rise. The recovery in vitro was determined by expressing the factor VIII content of cryoprecipitate packs as a percentage of the content of the corresponding donor plasma packs.

\section{RESULTS}

Data are available from 101 packs of cryoprecipitate produced by the quick thaw method using fresh blood. This was the standard method of production at this centre and packs were produced by this method throughout the period of the investigation. Analysis of the contents of individual packs showed that there was no significant variation of the mean content of factor VIII during the period of the investigation and furthermore the mean content of 83 units (Table II) was very similar to that of 85 units obtained in an earlier series (Bloom and Emmanuel, 1968). These findings suggest that there was no significant alteration in this technique of cryoprecipitate production or factor VIII assay during the period of study. Data are also available for 67 packs produced by the slow thaw method using fresh blood, 102 packs produced by the quick thaw method using 24-hour-old blood, and 76 packs produced by the slow thaw method using 24-hourold blood. The data analysed include the factor VIII content of donor plasma, cryoprecipitate packs, and supernatant plasma, the recovery in vitro and loss of factor VIII, and the recovery in vivo in patients treated with the various types of cryoprecipitate.

FACTOR VIII CONTENT OF DONOR PLASMA The factor VIII content and volume of the donor plasma are 
shown in Table I. For all methods there was no significant difference in the volume of plasma processed. The mean factor VIII level of the stored frozen samples of fresh plasma were the same whether the corresponding packs had been processed by the slow or quick thaw methods but was only about $70 \%$ of the control average value of $100 \%$. The difference was partially due to the greater dilution with anticoagulant in the donor samples compared with the controls and probably also to loss during collection and freezing and thawing of the samples for assay. The mean factor VIII content of the frozen samples of 24-hour-old plasma was also the same irrespective of the method used for processing the corresponding packs but there was signicantly greater loss compared with fresh plasma, the mean factor VIII level being only about $50 \%$.

TABLE I

FACTOR VIII CONTENT AND VOLUME OF DONOR PLASMA

\begin{tabular}{|c|c|c|c|}
\hline \multicolumn{2}{|c|}{$\begin{array}{l}\text { Separated from } \\
\text { Fresh Blood }(A)\end{array}$} & \multicolumn{2}{|c|}{$\begin{array}{l}\text { Separated from } \\
\text { Twenty-four-hour } \\
\text { Blood }(B)\end{array}$} \\
\hline $\begin{array}{l}\text { Processed } \\
\text { by Quick } \\
\text { Thaw (C) }\end{array}$ & $\begin{array}{l}\text { Processed } \\
\text { by Slow } \\
\text { Thaw }(D)\end{array}$ & $\begin{array}{l}\text { Processed } \\
\text { by Quick } \\
\text { Thaw (E) }\end{array}$ & $\begin{array}{l}\text { Processed } \\
\text { by Slow } \\
\text { Thaw }(F)\end{array}$ \\
\hline $\begin{array}{c}101 \\
69 \pm 25\end{array}$ & $\begin{array}{c}67 \\
74 \pm 21\end{array}$ & $47^{102} \pm 22$ & $\begin{array}{c}76 \\
48 \pm 21\end{array}$ \\
\hline $226 \pm 32$ & $215 \pm 31$ & $218 \pm 24$ & $228 \pm 23$ \\
\hline $155 \pm 59$ & $160 \pm 56$ & $105 \pm 51$ & $110 \pm 44$ \\
\hline $\begin{array}{l}\mathbf{A} \text { vs } \mathbf{B} \\
\mathbf{P}=<0.0\end{array}$ & $01 \quad \begin{array}{l}C \text { vs D } \\
\mathrm{P}=>\end{array}$ & $\begin{array}{l}E \mathbf{v} \\
\mathbf{P}=\end{array}$ & $\begin{array}{l}\text { S F } \\
=0.4\end{array}$ \\
\hline
\end{tabular}

FACTOR VIII CONTENT OF CRYOPRECIPITATE The factor VIII content of cryoprecipitate is shown in Table II. The slow thaw technique produced a significantly more potent concentrate than the quick thaw method and, as would be expected, the packs produced from fresh blood contained more factor VIII than those produced from 24-hour-old blood. The packs produced from fresh blood by the slow thaw method were thus the most potent with a mean content of 112 units, but a reasonably active concentrate was produced from 24-hour-old blood by the slow thaw method with a mean content of 72 units. In order to confirm the relationship between factor VIII content of donor plasma and cryoprecipitate these values are shown graphically in Figure 1. This confirms that there is a positive correlation between factor VIII content of the donor plasma and that of the cryoprecipitate packs and also demonstrates the higher factor VIII content of fresh as opposed to 24-hour-old plasma. The increased recovery by the slow thaw method is shown by the
TABLE II

FACTOR VIII CONTENT OF CRYOPRECIPITATE AND SUPERNATANT PLASMA

\begin{tabular}{lll} 
Fresh Blood & \multicolumn{2}{c}{$\begin{array}{l}\text { Twenty-four- } \\
\text { hour Blood }\end{array}$} \\
\cline { 1 - 1 } $\begin{array}{l}\text { Quick Slow } \\
\text { Thaw }(A)\end{array}$ & Thaw (B) & $\begin{array}{l}\text { Quick } \\
\text { Thaw }(C)\end{array}$ Thaw Thaw $(D)$
\end{tabular}

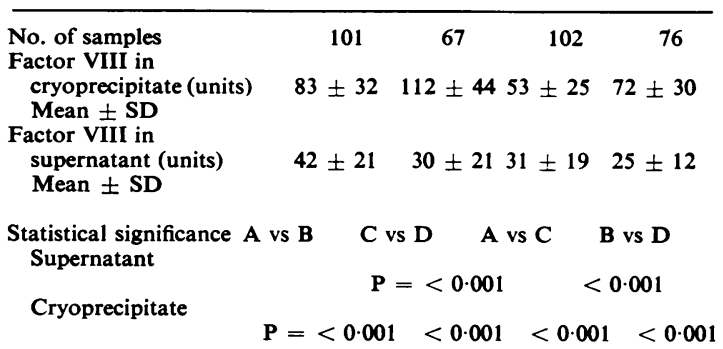

shift of the slope to the right. The wide range of factor VIII content of cryoprecipitate packs is also demonstrated in the figure.

FACTOR VIII CONTENT OF SUPERNATANT PLASMA The factor VIII content of the supernatant plasma is shown in Table II. There was a significantly greater quantity in the supernatant resulting from the quick thaw method using both fresh and 24-hour-old blood. The lower factor VIII content of the cryoprecipitate produced by the quick thaw process may therefore be partly due to loss by solution into the supernatant plasma.

RECOVERY AND LOSS OF FACTOR VIII In Vitro The percentage recovery in vitro and loss of factor VIII are shown in Table III. With both fresh and 24-hour-

TABLE III

AVERAGE IN VITRO RECOVERY AND LOSS OF FACTOR VIII DURING PREPARATION OF CRYOPRECIPITATE

\begin{tabular}{|c|c|c|c|c|}
\hline & \multicolumn{2}{|c|}{ Fresh Blood } & \multicolumn{2}{|c|}{$\begin{array}{l}\text { Twenty-four- } \\
\text { hour Blood }\end{array}$} \\
\hline & $\begin{array}{l}\text { Quick } \\
\text { Thaw }\end{array}$ & $\begin{array}{l}\text { Slow } \\
\text { Thaw }\end{array}$ & $\begin{array}{l}\text { Quick } \\
\text { Thaw }\end{array}$ & $\begin{array}{l}\text { Slow } \\
\text { Thaw }\end{array}$ \\
\hline $\begin{array}{l}\text { Recovery in cryoprecipitate }(\%) \\
\text { Recovery in supernatant }(\%) \\
\text { Loss }(\%)\end{array}$ & $\begin{array}{l}54 \\
26 \\
20\end{array}$ & $\begin{array}{l}70 \\
19 \\
11\end{array}$ & $\begin{array}{l}51 \\
29 \\
20\end{array}$ & $\begin{array}{l}66 \\
23 \\
11\end{array}$ \\
\hline
\end{tabular}

old blood the recovery is of the order of $70 \%$ with the slow thaw method but only about $50 \%$ with the quick thaw technique. The lower recovery was not only due to increased loss into the supernatant plasma but also to a greater loss apparently due to the technique itself.

RECOVERY OF FACTOR VIII In Vivo Cryoprecipitate produced by all four methods has been used to treat 


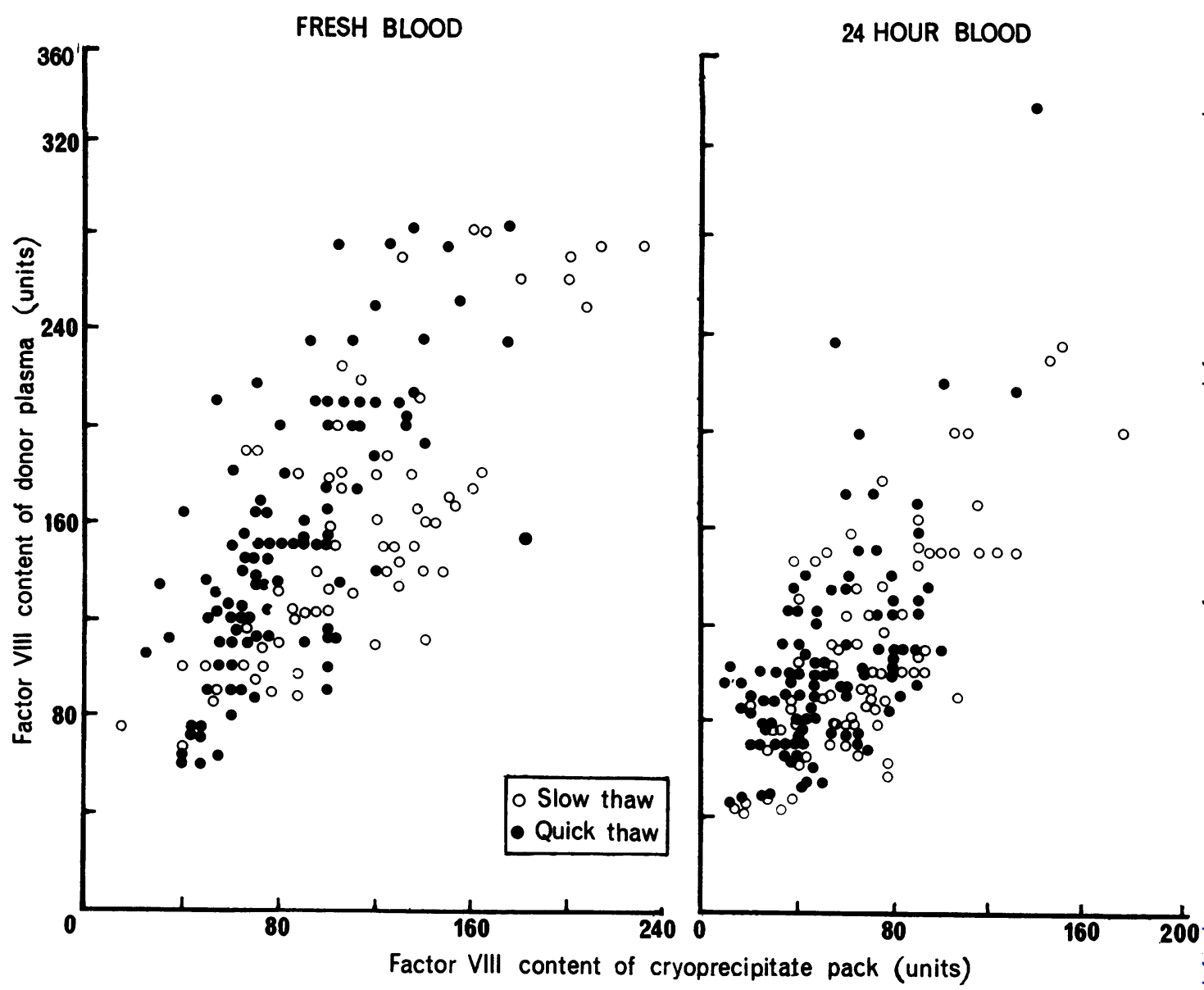

FIG. 1. Relationship of factor VIII content of cryoprecipitate to that of donor plasma separated from fresh and 0 24-hour-old blood and processed by slow and quick thaw methods. (Assays of donor plasma performed on stored $\stackrel{3}{.}$ frozen samples.)

Fresh blood: mean units of donor plasma, slow, 160 (SD 56), and quick, 155 (SD 59); mean units of cryoprecipitate, slow, 112 (SD 44), and quick, 83 (SD 32). Twenty-four-hour blood: mean units of donor plasma, 0 slow, 110 (SD 44), and quick, 105 (SD 51); mean units of cryoprecipitate, slow, 72 (SD 30), and quick, 53 (SD 25).

patients suffering from a variety of haemophilic lesions. The average size of doses and number of packs administered are shown in Table IV. In order to compensate for the anticipated lower recovery in vitro a greater number of packs of cryoprecipitate produced from 24-hour-old blood were used in each dose. The average rise of factor VIII per pack in patients was determined from the pre- and postinfusion assays and was adjusted to give the rise per pack expected if the patients weighed $70 \mathrm{~kg}$. From Table IV it can be seen that the cryoprecipitate produced by the slow thaw method or from fresh blood tended to give a greater rise of factor VIII per pack than that produced by the quick thaw method or from older blood, but the differences were not statistically significant. The mean recoveries in vivo of factor VIII are also shown in Table IV and varied $\sigma$ from 71 to $97 \%$. Although it was highest with N cryoprecipitate produced by the quick thaw method, $\underset{\omega}{\mathrm{N}}$ using 24-hour-old blood the differences were not statistically significant.

\section{DISCUSSION}

The slow thaw method of producing cryoprecipitate used in the present study was identical to that described by Pool and Shannon (1965), and the $\frac{}{1}$ recovery in vitro of $70 \%$ factor VIII was the same as that obtained by these workers. Furthermore the mean recovery in vitro of 112 units per pack was veryo 
TABLE IV

RECOVERY IN VIVO AND RISE OF FACTOR VIII IN PATIENTS TREATED WITH CRYOPRECIPITATE

\begin{tabular}{|c|c|c|c|c|}
\hline & \multicolumn{2}{|l|}{ Fresh Blood } & \multicolumn{2}{|c|}{$\begin{array}{l}\text { Twenty-four-hour } \\
\text { Blood }\end{array}$} \\
\hline & $\begin{array}{l}\text { Quick } \\
\text { Thaw }\end{array}$ & $\begin{array}{l}\text { Slow } \\
\text { Thaw }\end{array}$ & $\begin{array}{l}\text { Quick } \\
\text { Thaw }\end{array}$ & $\begin{array}{l}\text { Slow } \\
\text { Thaw }\end{array}$ \\
\hline No. of patients & 7 & 6 & 4 & 4 \\
\hline No. of doses & 13 & 8 & 8 & 6 \\
\hline $\begin{array}{l}\text { Average no. of packs } \\
\text { per dose }(70 \mathrm{~kg} \text { man) }\end{array}$ & $11 \cdot 1$ & $9 \cdot 3$ & $15 \cdot 4$ & $15 \cdot 3$ \\
\hline $\begin{array}{l}\text { Average dose per } \\
70 \mathrm{~kg} \text { man (units) }\end{array}$ & 929 & 1,091 & 814 & 1,050 \\
\hline $\begin{array}{l}\text { Rise of factor VIII per } \\
\text { pack ( } 70 \mathrm{~kg} \text { man) } \\
\text { Mean } \pm \text { SD }\end{array}$ & $2.1 \pm 0.59$ & $2.4 \pm 1.02$ & $21.6 \pm 0.86$ & $62.0 \pm 0.48$ \\
\hline $\begin{array}{l}\text { In vivo recovery }(\%) \\
\text { Mean } \pm \text { SD }\end{array}$ & $83 \pm 27$ & $71 \pm 32$ & $97 \pm 37$ & $92 \pm 17 \cdot 5$ \\
\hline
\end{tabular}

similar to that of 113 units per pack obtained by Prentice, Breckenridge, Forman, and Ratnoff (1967) using this technique. According to Brown et al (1967), a more potent concentrate can be produced by their quick thaw method. Our results, however, have shown that the concentrate produced by the slow thaw method was significantly more potent, with less loss into the supernatant and less loss due to the technique itself. Bennett, Dormandy, Churchill, Coward, Smith, and Cleghorn (1967) have also compared the slow and quick thaw methods. They failed to detect any significant difference between the resultant cryoprecipitate, although the plasma processed by the quick method contained more factor VIII than that processed by the slow method. They noted that there was a greater loss into the supernatant plasma with the quick method, a finding similar to our own observations. The difference between the findings of Bennett et al (1967) and ourselves on the one hand and those of Brown et al (1967) may be explained by a slight difference of technique. In both the present study and that of Bennett et al, the Fenwal JD-2 double packs were used in order to preserve sterility. Brown and his colleagues sacrificed the closed bag system and transferred plasma to larger packs. They were thus able to flatten the packs and obtain more rapid freezing. It is not certain if this is the explanation for the different findings, but our results suggest that for routine production of cryoprecipitate using the JD-2 double packs, the slow thaw method produces the most potent concentrate.

Another disadvantage of the Fenwal JD-2 system is that the volume of plasma transferred to the small satellite pack must be limited in order to prevent it rupturing when frozen. With their method Brown et al (1967) overcame this disadvantage and were able to process a greater volume of plasma from each donor. The yield of factor VIII from each donor may have been thereby increased, but, according to their own data, this was not the explanation for the greater percentage recovery claimed for the quick thaw method.

Factor VIII is labile so that, ideally, donors should be bled in a room adjacent to the laboratory and the plasma separated and processed immediately. These facilities apparently exist in certain hospital laboratories and in transfusion services situated in large urban centres (Prentice et al, 1967; Brown et al, 1967; Bennett et al, 1967). The increasing demand for cryoprecipitate has, however, resulted in the use of several thousand packs each year in individual haemophilia centres. It may not be desirable for such large numbers of donors to attend hospital laboratories and it may not even be practicable for all the blood to be collected at the transfusion centre. Blood therefore must often be collected at routine donor sessions and transported, sometimes as far as 30 miles, to the transfusion centre for processing. In areas where the population is scattered there may thus be some delay before the blood reaches the transfusion centre and comparatively large batches of blood may arrive at one time. It may be more convenient to process some of the blood on the day after collection and for this reason we have considered it necessary to investigate the potency of cryoprecipitate produced from 24hour-old blood.

Studies of factor VIII levels in stored blood have produced conflicting results. Penick and Brinkhous (1956) observed that $70 \%$ of factor VIII remained in blood stored at $+4^{\circ} \mathrm{C}$ for seven days in glass bottles and Goldstein et al (1964) obtained similar results with blood stored in plastic packs. On the other hand Pool and Robinson (1959b) noted a loss of up to $50 \%$ even in fresh plasma, due partly to dilution with the extra anticoagulant of bank blood, and partly due to centrifugation at temperatures above $+4^{\circ} \mathrm{C}$. Preston (1967) observed figures between these values with $21 \%$ loss during the first 24 hours and $55 \%$ loss after one week in blood stored at $+4^{\circ} \mathrm{C}$. He observed factor VIII levels of $66 \%$ in one series of samples of ACD blood stored for 18 hours at $+4^{\circ} \mathrm{C}$. We have found it convenient to store samples of plasma at $-30^{\circ} \mathrm{C}$ before assay and this may partly account for our finding of a mean factor VIII level of only $70 \%$ in 'fresh', ie, up to four-hourold plasma. This finding is neverthelesss in agreement with the observations of Pool and Robinson (1959b) and Biggs, Matthews, Rush, Johnstone, MacFarlane, and Hayton-Williams (1965) that 'fresh frozen plasma' contains about $65 \%$ factor VIII activity. The factor VIII activity in the 24-hour-old plasma in the present study was $50 \%$ and this therefore represents a loss of about $30 \%$ of the original activity. 
Our results have confirmed that the potency of cryoprecipitate is proportional to the factor VIII content of donor plasma and that the best results are obtained with fresh blood. A useful concentrate can, however, be produced from 24-hour-old blood, particularly when it is prepared by the slow thaw technique. There is moreover no evidence that the delay in processing causes qualitative alteration of factor VIII because the recovery in vivo was not significantly different from that obtained with cryoprecipitate produced from fresh blood. According to Weaver, Gabriel, and Langdell (1967) factor VIII can even be salvaged from outdated bank blood by the cryoprecipitate process but we have not yet investigated this possibility.

A possible disadvantage of using cryoprecipitate prepared from stored blood is that concentrate from a greater number of donors is needed to produce a desired response. This may increase the risks of adverse reactions and serum hepatitis as well as the risk of developing an inhibitor of factor VIII. For this reason we do not advise the routine preparation of cryoprecipitate from 24-hour-old blood but suggest that this could be a useful method of supplementing supplies during an emergency or during periods of excessive demand.
We wish to thank the consultant staff of the Medicalo Unit and the paediatricians for allowing one of us: (A.L.B.) to supervise the haematological management o $\overline{5}$ patients admitted to their beds at Cardiff Royal InfirmaryWe also wish to thank Miss M. Bollard, AIMLT, for helpo in performing factor VIII assays.

\section{REFERENCES}

Bennett, E., Dormandy, K. M., Churchill, W. G. L., Coward, A. R. $\overrightarrow{0}$ Smith, M., and Cleghorn, T. E. (1967). Brit. med. J., 2, 88.

Biggs, R., and Matthews, J. M. (1966). In Treatment of Haemophilia and Other Coagulation Disorders, edited by R. Biggs and R. GW MacFarlane, p. 107. Blackwell, Oxford.

,-- , Rush, B. M., Johnstone, F. C., MacFarlane, R. G., an Hayton-Williams, D. S. (1965). Lancet, 1, 969.

Bloom, A. L., and Emmanuel, J. H. (1968). Quart. J. Med., 37, $291 \mathrm{~N}$ Brown, D. L., Hardisty, R. M., Kosoy, M. H., and Bracken, C. (1967) Brit. med. J., 2, 79.

Goldstein, R., Bunker, J. P., and McGovern, J. J. (1964). Ann. N.Y Acad. Sci., 115, 422. Mollison, P. L. (1967). Blood Transfusion in Clinical Medicine, 4th ed음
Blackwell, Oxford.

Penick, G. D., and Brinkhous, K. M. (1956). Amer. J. med. Sci., 232, 434.

Pool, J. G., and Robinson, J. (1959a). Brit. J. Haemat., 5, 17. (1959b). lbid., 5, 24.

- , and Shannon, A. E. (1965). New Engl. J. Med., 273, 1443.

Prentice, C. R. M., Breckenridge, R. T., Forman, W. B., and Ratnoff O. D. (1967). Lancet, 1, 457.

Preston, A. E. (1967). Brit. J. Haemat., 13, 42.

Weaver, R. A., Gabriel, D. A., and Langdell, R. D. (1967). Transfusion, 7, 168.

Wolf, P. (1959). Brit. J. Haemat., 5, 169.

\section{Reports and Bulletins prepared by the Association of Clinical Biochemists}

The following reports and bulletins are published by the Association of Clinical Biochemists. They may be obtained from The Administrative Office, Association of Clinical Biochemists, 7 Warwick Court, Holborn, London, W.C.1. The prices include postage, but airmail will be charged extra. Overseas readers should remit by British Postal or Moneyo̊ Order. If this is not possible, the equivalent of $10 \mathrm{~s}$. is the minimum amount that can be accepted.

\section{SCIENTIFIC REPORTS}

1 Colorimeters with Flow Through Cells. A critical assessment of 4 instruments. 1965. P. M. G. BROUGHTON and C. RILEY. 13s. $6 \mathrm{~d}$.

2 Colorimeters. A critical assessment of 5 commercial instruments. 1966. P. M. G. BROUGHTON, C. RILEY, J. G. H. COOK, P. G. SANDERS, and H. BRAUNSBERG. $15 \mathrm{~s}$.

3 Automatic Dispensing Pipettes. An assessment of 35 commercial instruments. 1967. P. M. G. BROUGHTON, A. H. GOWENLOCK, G. M. WIDDOWSON, and K. A. AHLQUIST. 10s.

\section{TECHNICAL BULLETINS}

9 Determination of Urea by AutoAnalyzer. November 1966. RUTH M. HASLAM. 2s. 6 d.
11 Determination of Serum Albumin by AutoAnalyzer using Bromocresol Green. October 1967. B. E.음 NORTHAM and G. M. WIDDOWSON. 2s. $6 \mathrm{~d}$.

12 Control Solutions for Clinical Biochemistry. February $\mathcal{O}^{2}$ 1968. P. M. G. BROUGHTON. 2s. 6 d.

13 An Assessment of the Technicon Type II Sampler Unit. March 1968. B. C. GRAY and G. K. MCGOWAN. 1s. 6d.

14 Atomic Absorption Spectroscopy. An Outline of its Principles and a Guide to the Selection of Instruments. May 1968. J. B. DAWSON and P. M. G. $\frac{\stackrel{\rho}{\Phi}}{\varrho}$
BROUGHTON. 4s.

15 A Guide to Automatic Pipettes (2nd edition). June 1968. P. M. G. BROUGHTON. $5 \mathrm{~s}$. 
a low production of pigment on normal media, according to all the other biochemical tests showed them to be normal $P$. aeruginosa strains; this was confirmed by the results of the growth on the milk agar, both hydrolysis of the casein and pigment production being observed. In the case of the other two strains, 950 and 5940, the position was not so straightforward. Neither produced pigment on any of the solid media, including the milk agar. They did, however, show some signs of hydrolysis of the casein, and this increased on incubation for a further 48 hours, but no pigment was demonstrable. The results of the biochemical tests likewise showed that these two strains did not conform precisely to the $\boldsymbol{P}$. aeruginosa or the $\boldsymbol{P}$. fluorescens patterns, but in fact have some characters common to both, and these can be regarded as intermediate fluorescens/aeruginosa types. This is supported by the results of the milk agar media previously discussed. Indeed, in view of the recently demonstrated high transformation frequency within the genus Pseudomonas (Khan and Sen, 1967), the existence of such intermediate strains is not surprising. In either case, the milk agar has shown itself to be as reliable as the more conventional biochemical tests.

We wish to thank Dr S. P. Lapage, of the National Collection of Type Cultures, for kindly supplying the poorly pigmented strains of $P$. aeruginosa, and Dr M. T. Parker, of Central Public Health Laboratory, Colindale, London, NW9, for kindly carrying out the phage typing. We also wish to thank The Medical Research Council for a grant which supported part of this work.

\section{References}

Colwell, R. R. (1964). J. gen. Microbiol., 37, 181-194. A study of features used in the diagnosis of Pseudomonas aeruginosa.

Cowan, S. T., and Steel, K. J. (1965). Manual for the Identification of Medical Bacteria. Cambridge University Press, London.

Gaby, W. L., and Free, E. (1953). Occurrence and identification of nonpigmented strains of Pseudomonas aeruginosa in the clinical laboratory. J. Bact., 65, 746.

Gaby, W. L, and Free, E. (1958). Differential diagnosis of Pseudomonas-like microorganisms in the clinical laboratory. J. Bact., 76, 442-444

Haynes, W. C. (1951). Pseudomonas aeruginosa-its characterisation and identification. J. gen. Microbiol., 5, 939-950.

Hugh, R., and Leifson, E. (1953). The taxonomic significance of fermentative versus oxidative metabolism of carbohydrates by various gram negative bacteria. J. Bact., 66, 24-26.

Khan, N. C., and Sen, S. P. (1967). Genetic transformation in Pseudomonas. J. gen. Microbiol., 49, 201-209.

King, E O., Ward, M. K., and Raney, D. E. (1954). Two simple media for the demonstration of pyocyanin and fluorescin. J. Lab. clin. Med., 44, 301-307.

Kovacs, N. (1956). Identification of Pseudomonas pyocyanea by the oxidase reaction. Nature (Lond.), 178, 703.

Lysenko, O. (1961). Pseudomonas-An attempt at a general classification. J. gen. Microbiol., 25, 379-408.

Phillips, I. (1969). Identification of Pseudomonas aeruginosa in the clinical laboratory. J. Med. Microbiol., 2, 9-16.

Preston, N. W., and Morrell, A. (1962). Reproducible results with the gram stain. J. Path. Bact., 84, 241-243.
Rhodes, M. E. (1959). The characterization of Pseudomonas fluorescens. J. gen. Microbiol., 21, 221-263.

Rhodes M. E., (1961). The characterization of Pseudomonas fluorescens with the aid of an electronic computer. J. gen. Microbiol., 25, 331-345

Rogers, K. B. (1963). Oxidase reaction. (Letter), Lancet, 2, 682.

Stanier, R. Y., Palleroni, N. J., and Disudoroff, M. (1966). The aerobic psuedomonads: a taxonomic study. J. gen. Microbiol., 43, 159-271.

Wahba, A. H., and Darell, J. H. (1965). The identification of atypical strains of Pseudomonas aeruginosa. J. ger. Microbiol., 38, 329-342.

\section{Errata}

In Table II in the paper entitled, 'Comparison of quick and slow thaw methods of producing cryoprecipitate antihaemophilic factor from fresh and 24-hour-old blood' A. L. Bloom (J. clin. Path., 22, 447-452) the $P$ values for the supernatant have been printed under the wrong headings. The correct table 'Factor VIII content of cryoprecipitate and supernatant plasma', is printed below.

\begin{tabular}{|c|c|c|c|c|}
\hline & \multicolumn{2}{|c|}{ Fresh Blood } & \multicolumn{2}{|c|}{$\begin{array}{l}\text { Twenty-four Hour } \\
\text { Blood }\end{array}$} \\
\hline & $\begin{array}{l}\text { Quick- } \\
\text { Thaw } \\
\text { (A) }\end{array}$ & $\begin{array}{l}\text { Slow- } \\
\text { Thaw } \\
\text { (B) }\end{array}$ & $\begin{array}{l}\text { Quick- } \\
\text { Thaw } \\
\text { (C) }\end{array}$ & $\begin{array}{l}\text { Slow- } \\
\text { Thaw } \\
\text { (D) }\end{array}$ \\
\hline Number of sample & 101 & 67 & 102 & 76 \\
\hline $\begin{array}{l}\text { Factor VIII in } \\
\text { cryoprecipitate } \\
\text { units) Mean } \pm S D\end{array}$ & $83 \pm 32$ & $112 \pm 44$ & $53 \pm 25$ & $72 \pm 30$ \\
\hline $\begin{array}{l}\text { Factor VIII in } \\
\text { supernatant (units) } \\
\text { Mean } \pm \text { SD }\end{array}$ & $42 \pm 21$ & $30 \pm 21$ & $31 \pm 19$ & $25 \pm 12$ \\
\hline $\begin{array}{l}\text { Statistical } \\
\text { significance }\end{array}$ & $A \cup B$ & $C \vee D$ & $C$ & $D$ \\
\hline Supernatant & $P=<0.001$ & $P=<0.001$ & & \\
\hline Cryoprecipitate & $P=<0.001$ & $P=<0.001$ & $<0.001$ & $=<0.001$ \\
\hline
\end{tabular}

In Table IIa of the paper by Davis et al, J. Clin. Path., 1969, 22, 634, the figures for Proteus mirabilis under the columns for tetracycline should read: S: $9.7 \%$, 'S': $0.9 \%$ and $R: 89.4 \%$; the mean percentages of total should therefore read: $S: 30.8 \%$; 'S': $6 \cdot 1 \%$; R: $63 \cdot 1 \%$. 